\title{
SOCIAL FINANCE
}

Theresa Kuchler

Johannes Stroebel

Working Paper 27973

http://www.nber.org/papers/w27973

\author{
NATIONAL BUREAU OF ECONOMIC RESEARCH \\ 1050 Massachusetts Avenue \\ Cambridge, MA 02138 \\ October 2020
}

Both authors have been research consultants at Facebook, a social networking company, in order to work with anonymized data on research topics in the "social finance" space. The views expressed herein are those of the authors and do not necessarily reflect the views of the National Bureau of Economic Research.

NBER working papers are circulated for discussion and comment purposes. They have not been peer-reviewed or been subject to the review by the NBER Board of Directors that accompanies official NBER publications.

(C) 2020 by Theresa Kuchler and Johannes Stroebel. All rights reserved. Short sections of text, not to exceed two paragraphs, may be quoted without explicit permission provided that full credit, including $\odot$ notice, is given to the source. 
Social Finance

Theresa Kuchler and Johannes Stroebel

NBER Working Paper No. 27973

October 2020

JEL No. G0

\begin{abstract}
We review an empirical literature that studies the role of social interactions in driving economic and financial decision making. We first summarize recent work that documents an important role of social interactions in explaining household decisions in housing and mortgage markets. This evidence shows, for example, that there are large peer effects in mortgage refinancing decisions and that individuals' beliefs about the attractiveness of housing market investments are affected by the recent house price experiences of their friends. We also summarize the evidence that social interactions affect the stock market investments of both retail and professional investors as well as household financial decisions such as retirement savings, borrowing, and default. Along the way, we describe a number of easily accessible recent data sets for the study of social interactions in finance, including the "Social Connectedness Index," which measures the frequency of Facebook friendship links across geographic regions. We conclude by outlining several promising directions for further research at the intersection of household finance and "social finance."
\end{abstract}

Theresa Kuchler

Stern School of Business

New York University

44 West 4th Street

New York, NY 10012

and NBER

tkuchler@stern.nyu.edu

Johannes Stroebel

Stern School of Business

New York University

44 West 4th Street

New York, NY 10012

and NBER

johannes.stroebel@nyu.edu 


\section{Introduction}

Researchers have long understood that social interactions shape many aspects of economic activity. Yet, in most models of economics and finance, agents make financial decisions in a social vacuum in which prices are the only mechanism through which the behavior of other agents affects beliefs and behaviors. This is likely to change substantially over the coming years. Indeed, the availability of new data has facilitated a recent surge of empirical research documenting large effects of social interactions on the economic and financial decisions of households and firms. Many of the documented effects are too large for theory to ignore, and there has been early progress in incorporating social interactions in equilibrium models of economic decision making. This trend is only going to accelerate as novel data sets on the social structure of society become increasingly available to researchers.

In this paper, we review a number of recent contributions to the field of "social finance," a term popularized by Hirshleifer (2020) for the study of how social processes shape economic outcomes. In the spirit of the Annual Review of Financial Economics, we do not provide an encyclopedic overview of the literature. Instead, we describe several recent and primarily empirical studies at the frontier of social finance. In doing so, we largely focus on research studying the role of social interactions and peer effects in explaining the financial decisions of households. Our objective is to provide interested readers with a starting point to conduct their own work at the intersection of social finance and household finance.

Some of the earliest work studying peer effects in household finance explored how the financial investments of individuals were influenced by their families, friends, and acquaintances. More recently, the focus of research has expanded to cover household financial behavior across a wider range of settings and questions. First, following the Global Financial Crisis of 2008, an emerging research priority has been to better understand how households make decisions in housing and mortgage markets, and a number of recent studies have shown that social interactions turn out to play an important role in shaping these decisions. We begin our review below by summarizing some of the key findings from that body of work. Second, the literature moved beyond documenting the mere existence of peer effects for investment decisions to (i) studying the mechanisms behind these peer effects, and (ii) exploring the impact of peer effects on equilibrium market level outcomes. We review this work before turning our attention to households' savings and debt accumulation decisions outside of the housing and mortgage market. Along the way, we point out useful data sets for the study of social finance. We focus particularly on the publicly available "Social Connectedness Index," which captures the social connectedness between geographic regions based on friendship links on Facebook, the world's largest social networking site. We conclude by highlighting interesting directions for future work.

Before reviewing recent contributions to the social finance literature, we next characterize the broad mechanisms through which peers can influence individual behavior. We also describe a number of common challenges in most of the empirical research in social finance as well as some techniques to deal with these challenges. 


\subsection{Potential Mechanisms Underlying Peer Effects}

Social interactions can influence people's economic and financial decisions through several channels, with two mechanisms featuring particularly prominently in narratives of social finance. We find them to provide a useful organizing framework for thinking about peer effects, even if not all peer effects can be neatly mapped to these broad categories, and some observed peer effect might be the result of both mechanisms operating at the same time.

First, social networks can serve as a source of information, and individuals might thus be affected by their peers through a "social learning" channel (e.g., Bikhchandani et al., 1992; Jackson, 2010). It is indeed plausible that individuals rely on their social networks for information on important financial decisions. In particular, many of these decisions - such as buying a home, taking out a mortgage, and purchasing stocks - are rare, which means that most individuals do not have much experience in making these decisions. In addition, many other possible sources of information, such as mortgage brokers and investment advisers, have real or perceived conflicts of interest with the individuals they are supposed to advise. As a result, friends, colleagues, and family members remain as a potential source of unbiased information and advice, in particular if they have own experiences relevant to the decision at hand.

Second, peers' actions can directly enter individuals' utility functions, allowing peer effects to also operate through a "social utility" channel. For example, individuals may have preferences that weight relative differences between their own consumption and the consumption of their peers (e.g., Duesenberry et al., 1949; Abel, 1990). Such preference may then cause individuals to mimic the consumption patterns of others in order to "keep up with the Joneses." Alternatively, a fear of missing out on a particularly attractive investment might encourage individuals to copy the investment decisions of their friends.

\subsection{Common Empirical Challenges}

There are substantial empirical challenges to documenting a causal effect of social interactions on economic decision making, with problems of both measurement and identification looming large. Since these challenges are common to much of the empirical work we discuss below, we next review the most prevalent problems and approaches to solving them.

Measurement. On the measurement side, it is usually necessary to observe both the outcome variable of interest as well as a peer group within the same data set. To overcome this hurdle, researchers often rely on definitions of peer groups that include geographic neighbors, work colleagues, or family members, in part because location of residence and employer are regularly collected in administrative data. As we discuss in more detail below, recent research has also used information from social networking platforms such as Facebook and LinkedIn to measure social networks. This allows researchers to substantially expand the set of peer interactions that can be studied.

Identification. A pervasive identification challenge in the empirical peer effects literature is

to separate the influence of peer decisions on choices from the effects of selection in friendship 
groups and the exposure to common shocks (see Manski, 1993). One reason for these challenges is that endogenously formed peer groups often contain people with similar characteristics and preferences - a feature called homophily (McPherson et al., 2001). As a result, correlated behavior across friends does not necessarily imply the presence of peer effects. For example, when two friends purchase a new iPhone at the same time, this could be due to peer effects, with one friend influencing the purchasing decision of the other. However, such correlated purchasing could also occur if two tech-savvy individuals, both of whom independently want the iPhone, are more likely to be friends with one other. Similarly, peers often face correlated shocks. For example, two neighbors who are friends might be exposed to similar local iPhone advertising campaigns, providing yet another channel that could explain an observed correlation in their phone purchases.

The literature has proposed two types of research designs to overcome this identification challenge from homophily in endogenously formed peer groups: random peer group assignment and random shocks to an existing peer group.

The first approach involves exploiting randomized assignments of individuals to peer group settings, for example, through random allocation to military units or college dorms. Alternatively, lab experiments allow researchers to vary group composition randomly. The idea is that when individuals are assigned to settings at random, this eliminates any excessive within-setting correlation in preferences and characteristics resulting from homophily. However, even when friendship groups are randomly assigned, correlated behavior across individuals could still be the result of common shocks that affect all members of the group. For example, when two college roommates purchase new phones at the same time, this could in part be explained by both of them remembering the same television ad they viewed together, even if the initial room assignment was random. As a result, researchers using research designs with random group assignment need to argue that correlated shocks cannot explain their findings.

An alternative research design exploits random shocks to the behavior of friends in an endogenously formed peer group. In this case, researchers need to argue that the random shock should not affect an individual's own behavior except through peer effects from her friends who receive the shock. For example, if my friend breaks her phone, this should only influence my own desire to buy a new phone through the peer effects from her replacement purchase (see Bailey et al., 2019b). These random shocks to a subset of friends can also be induced experimentally, as a number of researchers have done (e.g., Mobius et al., 2005).

\section{Peer Effects in Housing and Mortgage Markets}

The housing market is a natural place where social interactions might be important. Housing decisions involve large amounts of money, are infrequent, and are conducted in markets that are localized, segmented, and subject to multiple dimensions of information asymmetries (see Kurlat \& Stroebel, 2015; Stroebel, 2016; Piazzesi et al., 2020). As a result, it seems natural for individuals to consult with members of their social networks about questions such as: "What should I pay for this house?"; "Is this a good neighborhood for kids?"; "Which broker should I use?"; "What type 
of mortgage should I take?"; and "Should I default on my mortgage?" Similarly, given the salient nature of individuals' housing consumption, a desire to "keep up with the Joneses" could be an important motivation in the housing market. In this section, we review several recent papers that indeed document an important role for various social interactions in explaining a wide range of housing and mortgage market decisions.

\subsection{Belief Contagion in the Housing Market}

One important channel through which social interactions can affect housing market decisions is by influencing people's perceptions of whether buying a house is a good idea from an investment perspective. Indeed, Robert Shiller has long argued that house prices are, to a substantial extent, driven by belief fluctuations that are the result of social interactions. For example, Shiller (2007) wrote that "many people seem to be accepting that the recent home price experience is at least in part the result of a social epidemic of optimism for real estate." In this narrative, which often borrows language from the epidemiology literature, individuals who observe recent price increases and become more optimistic subsequently "infect" their friends with this optimism. However, while the idea of social dynamics in housing markets has been around for some time, there has been little empirical evidence for whether optimism and pessimism are truly "contagious" in the way proposed by Shiller.

Bailey et al. (2018a) were among the first to provide direct empirical evidence for belief contagion in the housing market. They document that individuals whose far-away friends experienced higher recent house price growth are indeed more optimistic about future local house price growth. This increased optimism translates into actual changes in their housing market behavior. Specifically, people whose friends experienced larger recent house price gains are more likely to buy a house and more likely to buy a larger house. They are also willing to pay more for a given house.

To measure an individual's social network, Bailey et al. (2018a) collaborate with Facebook, the world's largest online social networking service with 2.6 billion users worldwide and 253 million users in the U.S. and Canada. The empirical analysis begins by documenting that, at any point in time, different people in the same local housing market have friends who have experienced vastly different recent house price movements. This variation is driven by heterogeneity in the location of individuals' friends, combined with variation in regional house price changes. Bailey et al. (2018a) then provide evidence for an important effect of social interactions on an individual's assessment of the attractiveness of local property investments. For this analysis, they field a survey among Los Angeles-based Facebook users. Over half of the survey respondents report that they regularly talk to their friends about investing in the housing market. The survey also asked respondents to assess the attractiveness of property investments in their own zip codes. The authors find a strong positive relationship between the recent house price experiences of a respondent's friends and whether that respondent believes that local property is a good investment. Importantly, this relationship is stronger for individuals who report that they regularly talk with their friends about investing in property. For individuals who report to never talk to their friends 
about investing in the housing market, there is no relationship between friends' house price experiences and own evaluations of the attractiveness of housing investments. These results suggest that social interactions provide a natural link between friends' house price experiences and an individual's own housing market expectations.

Bailey et al. (2018a) then show that friends' house price experiences do not just affect an individual's housing market expectations, but also her actual housing market investments. To conduct this analysis, the authors combine deidentified Facebook social network data with anonymized public record information on individuals' housing transactions. The economic magnitudes of the effects of friends' experiences on own behavior are large. In particular, a 5 percentage point higher average house price growth between 2008 and 2010 in the counties where an individual has friends leads to a 3 percentage point increase in the probability of that individual transitioning from being a renter in 2010 to being a homeowner in 2012. This is more than half the effect size of adding a family member and is a large effect relative to a baseline transition probability of 18 percent. Conditional on an individual buying a house, a 5 percentage point increase in friends' house price experiences over the 24 months prior to the purchase is associated with the individual buying a 1.6 percent larger property. And finally, conditional on observable property characteristics, a 5 percentage point increase in the house price experiences in an individual's social network is associated with that individual paying 2.3 percent more for the same property. Bailey et al. (2018a) provide evidence that the relationships between the house price experiences in an individual's social network and her housing market behavior capture a causal mechanism that works through the influence on beliefs.

Overall, the evidence in Bailey et al. (2018a) highlights that friends' house price experiences can affect an individual's own housing market assessments enough to substantially influence her housing market activity. This conclusion is consistent with the findings in Bayer et al. (2016), who show that many new housing market investors entered the market as a result of observing various forms of investment activity in their own neighborhoods. While these authors do not have access to survey data, one possible channel for this behavior is belief contagion, though other explanations, such as learning about the ease of investing in real estate, are also possible.

In related theoretical work, Burnside et al. (2016) explore how social dynamics at the individual level, such as those documented in Bailey et al. (2018a), can affect equilibrium housing market outcomes. In particular, Burnside et al. (2016) propose a model in which agents have heterogeneous expectations about long-run market fundamentals. The central ingredient of their model is that agents change their views as a result of social dynamics: they meet randomly, and those with tighter priors are more likely to convert other agents to their beliefs. The mechanism thus closely resembles epidemiological models of disease spread, whereby optimists "infect" their peers with their optimism. The model generates a "fad" in the sense that the fraction of the population with a particular view can rise and then fall without additional shocks. These fads can lead to boombusts or protracted booms in house prices. This paper thus highlights that "social dynamics" can have a large effect on equilibrium housing market outcomes. 
Importantly, the mechanism of belief adjustment proposed by Burnside et al. (2016) is far from the standard Bayesian or otherwise rational models of belief updating commonly found in the literature. Nevertheless, based on the evidence reviewed above, we believe that, in many markets, thinking of beliefs as spreading through a contagion-like process is an appropriate description of reality. As the economics profession becomes more comfortable with such deviations from rational behavior, we suspect that models enriched with social dynamics will have substantial success in explaining price and quantity movements across a large number of markets.

\section{2 "Keeping $U \mathrm{p}$ " in the Housing Market}

In addition to belief contagion, a second channel through which social interactions can affect housing market outcomes is through generating positional externalities. Bellet (2019) explores this mechanism and shows that the housing consumption of others lowers the utility that individuals derive from their own homes. Specifically, he finds that new construction at the top of the house size distribution in a neighborhood lowers the satisfaction that other residents derive from their own homes. The effect is quantitatively large: a $1 \%$ increase in the size of newly built houses at the top of the distribution almost offsets the satisfaction gains from a $1 \%$ increase in own home size. Consistent with these results, Bellet (2019) finds that the construction of large homes after a household has moved lowers the market value that homeowners ascribe to the size of their own houses. He also shows that existing owners of large houses strive to "keep up" with their neighbors and increase the size of their own homes in response to new large construction.

These results provide strong evidence that individuals do not just evaluate their housing situation in a social vacuum, but instead judge their own property relative to those of others. This finding allows us to rationalize the observed Easterlin paradox in housing consumption, whereby U.S. homeowners' satisfaction with their own homes has remained steady over time, despite a substantial increase in average home size in the past decades.

\subsection{Peer Effects in Mortgage Choice}

As with buying a house, taking out a mortgage is a rare and complicated procedure for many people. It is thus natural that individuals would rely on their social networks to obtain relevant information. Indeed, two recent papers have found evidence for peer effects in influencing individuals' mortgage choices.

Maturana \& Nickerson (2019) explore the role of workplace peers in providing information about mortgage refinancings. They study a sample of teachers from Texas, for which they are able to observe quasi-random variation in peer groups. In particular, the authors exploit that different teacher-pairs within the same school are more likely to interact when they share the same off-periods. Maturana \& Nickerson (2019) use this variation to document a strong effect of peer behavior on mortgage refinancing decisions: a teacher is $20.7 \%$ more likely to refinance their own mortgage following a one standard deviation increase in the refinancing activity among her peers. The effect of peer behavior increases with the potential savings realized upon refinancing, and is stronger among younger teachers. Peers also affect a teacher's choice of lender. 
In related work, McCartney \& Shah (2019) also provide evidence that households' refinancing decisions as well as the choice of lender and loan type are socially influenced by a peer group of their hyperlocal neighbors. Consistent with a word-of-mouth mechanism, households moving to new areas are not initially influenced by their immediate neighbors, but increasingly become so over time. In addition, non-occupant owners (who have less opportunity to interact with neighbors) are significantly less influenced than owner-occupants.

Both of these papers suggest that peer interactions can substantially affect households' decisions in the mortgage market, most likely by reducing the cost of acquiring and processing financial information. In other words, these studies show that neighbors and colleagues can be a crucial source of information for households' mortgage decisions. In many ways, this is not surprising, since many other potential sources of information, such as mortgage brokers, are not disinterested parties to the transaction. This leaves friends, colleagues, and family as sources of information without a direct financial interest in the eventual decision.

Bailey et al. (2019a) highlight that another way through which social interactions can influence mortgage choices is through influencing house price expectations. The authors introduce a simple model to describe how leverage choice is affected by beliefs about future house price growth. From a theoretical perspective, the relationship between house price expectations and leverage choice is ambiguous and depends on pessimistic households' ability to reduce their housing market exposure by renting or buying a smaller house. Specifically, one way for pessimistic household to reduce their housing market exposure could be through buying a smaller house or renting; all else equal, households would usually purchase the smaller home with less leverage to reduce their interest payments. However, they might not be able to do so for a variety of constraints, such as family size or job location. Instead of moving, these pessimistic households could instead reduce their exposure to the housing market by making a smaller downpayment (and thereby increasing their leverage) and anticipating to default in the case of large house price declines. In their empirical work, Bailey et al. (2019a) show that friends' house price experiences do indeed influence equilibrium leverage choices through their effects on house price beliefs. Specifically, they document that individuals with friends in states with recent house price declines become more pessimistic themselves. They consequently use more leverage to buy their homes, allowing them to reduce their direct financial exposure to future house price changes in their own neighborhoods. This effect is particularly large in states where default costs are relatively low, as well as in housing markets with few rental options. Importantly, in addition to the average house price experience across friends, other moments of the experience distribution also affect leverage choices. Specifically, Bailey et al. (2019a) show that individuals with friends from counties with a wider variety of house price experiences report wider distributions of expected house price changes. These wider belief distributions - which also correspond to larger probability weights placed on large house price declines - are also associated with smaller downpayments and increased leverage. 


\subsection{Peer Effects in Mortgage Default}

Several recent papers have also highlighted sizable peer effects in mortgage default behavior. Peer default can affect a person's own default probability through a number of channels, for example, by providing information about the cost of default or by changing the perceived social stigma of default.

In this literature, Guiso et al. (2013) use survey data to show that individuals appear more willing to default strategically if they are exposed to other people who strategically default. They find evidence that this is at least partly driven by information flows: knowing somebody who strategically defaulted reduces the perceived probability that a bank would go after a borrower who defaults. Consistent with this survey-based evidence, Gupta (2019) provides empirical evidence for social dynamics in foreclosures. He finds that each foreclosure filing leads to an additional 0.3 to 0.6 completed foreclosures within a 0.1-mile radius. He attributes this observed relationship to borrower responses arising from peer effects (in addition to price effects and bank-supply responses). This conclusion is also consistent with the evidence in Towe \& Lawley (2013), who study foreclosures in Maryland between 2006-2009. They show that a neighbor in foreclosure increases the hazard of additional defaults by 18 percent (defining a neighborhood as the 13 nearest neighbors). They argue that this effect goes beyond a temporary reduction in local house prices and implies a negative social multiplier effect of foreclosures.

\section{Peer Effects and the Behavior of Retail Investors}

Some of the earliest work on peer effects in financial decisions has shown the existence of peer effects in investment decisions. Indeed, both the extensive margin decision to participate in the stock market and the portfolio allocation decision appear to be influenced by similar decisions of a person's peers.

The fact that retail investors base their investment decisions at least partially on advice from their friends seems hardly surprising given the high-stakes and potentially intimidating nature of stock market investing. In fact, like most economists, we are frequently asked for investment advice from family and friends. We believe that this is, at least in part, because most other potential information sources have perceived or real conflicts of interest in the advice they provide. In addition to this "social learning" channel, an investment version of FOMO - the "fear of missing out" - can drive individuals to invest when they see their friends doing well in the stock market. This mechanism, which is related to the belief contagion in the housing market discussed above, is aptly characterized by Shiller (2000)'s description of Ponzi schemes: "That others have made a lot of money appears to many people as the most persuasive evidence in support of the investment story ... evidence that outweighs even the most carefully reasoned argument."

In early work studying the role of social networks in explaining retail investors' behavior, Ivković \& Weisbenner (2007) document a correlation in the stock purchasing behavior of retail investors that live near each other. Specifically, the authors find that a ten percentage point increase in neighbors' purchases of stocks from a certain industry is associated with a two percentage point 
increase in households' own purchases of stocks from that industry. Similarly, Feng \& Seasholes (2004) find that the behavior of Chinese retail investors is correlated with that of other nearby investors. Brown et al. (2008) and Hong et al. (2004) find evidence suggesting that the stock market participation decision is also influenced by social interactions with geographically close individuals: both papers document that individuals with more neighbors that participate in the stock market are also more likely to participate themselves. The authors argue that this geographic correlation in investment decisions is the result of peer effects and not the result of correlated preferences or correlated shocks. In more recent work on this question, Kaustia \& Knüpfer (2012) show that higher recent stock returns experienced by a person's local peers increase that individual's own likelihood of entering the stock market. In other words, it is not just the peers' participation decision but also their subsequent investment performance that has an effect on people's own entry decisions. Interestingly, while higher peer returns increase own participation, the effect diminishes for negative returns, suggesting that people do not share as much information about investments with inferior outcomes.

In addition to these papers, which focus on the effects on investing of geographically defined peer groups, several researchers have found correlations in the investment behaviors of work peers. For example, Hvide \& Östberg (2015) document a strong influence of coworkers on investment choices. They also conclude that following the trading behavior of a peer does not improve the quality of investment decisions, suggesting that work peers are not generally a source of unpriced information about stocks. Similarly, Ouimet \& Tate (2020) find that the choices of individuals to participate in an employee stock purchase plan influence their local coworkers' own decisions to participate in the program. In addition, local coworkers' trading patterns also affect individuals' own decisions to sell.

Beyond documenting the role of peer interactions in explaining individual investment choices, a number of recent studies have attempted to understand the reasons for this behavior. Bursztyn et al. (2014) design a field experiment to separately identify the effects of social learning and social utility from asset purchases by investors; they find that both channels play an important role. Arrondel et al. (2019) explore survey data to conclude that peer effects in investing are largely driven by individuals obtaining information about investing from their social circle, and less by mindless imitation. In related work, Frydman (2015) constructs an experimental asset market to investigate the mechanism behind peer effects in portfolio choice. He first confirms that a peer's portfolio allocation has a causal effect on a subject's own portfolio choice. Importantly, Frydman (2015) also collects data on the neural activity of his experimental subjects. He concludes that this neural data is consistent with a world in which relative wealth preferences play an important role in explaining the observed peer effects. In particular, he finds that neural activity in reward-related regions of the brain is increasing in a subject's own wealth, but decreasing in a peer's wealth. He also finds that individual differences in the strength of observed neural activity can explain crosssectional variation in portfolio choices, whereby the subjects with the strongest neural sensitivity to a peer's change in wealth are most influenced by a peer's investment decisions. 


\section{Peer Effects and the Behavior of Professional Investors}

We next review research that documents an important role of social interactions on investment decisions by professional investors. This research agenda follows early survey-based research by Shiller \& Pound (1989), who find that a sizable number of institutional investors report that their portfolio choices are driven in part by interpersonal communication. As with the retail investors described above, this is hardly surprising: friends and colleagues can be a welcome source of information or rumor for professionals trying to identify stocks that are likely to outperform. For example, given the size of the overall universe of assets, social interactions can make investors more aware of some stocks than they would otherwise be, particularly for small and otherwise opaque stocks.

A growing literature has since explored the effect of social interactions on the actual investment behavior of professional investors. Cohen et al. (2008) study connections between mutual fund managers and corporate board members via shared education networks. They find that portfolio managers place larger bets on firms they are socially connected to and perform significantly better on these holdings relative to their non-connected holdings. This second finding suggests that these education networks can be a source of useful information.

Similarly, Hong et al. (2005) show that the holdings and trades of mutual fund managers who work in the same city are correlated; however, while the evidence is highly suggestive, they cannot conclusively pin down social interactions as the source of the correlation. Pool et al. (2015) build on this work to show that the investment overlap between funds whose managers reside in the same neighborhood is considerably higher than that of funds whose managers live in the same city but in different neighborhoods. These correlations are also larger when managers share a similar ethnic background and are therefore more likely to interact with each other due to welldocumented homophily in social networks. These additional findings allow Pool et al. (2015) to rule out a number of alternative interpretations for the observed correlation in investment behavior. Pool et al. (2015) also conclude that valuable information is transmitted through these peer networks, allowing investors to outperform when investing in stocks they hear about through their local professional networks.

Kuchler et al. (2020a) further explore the role of social connections in explaining the investment behavior of professional investors. They use social network data from Facebook to show that institutional investors are more likely to invest in firms from regions to which they have stronger social ties. This effect of social proximity on investment behavior is distinct from the effect of geographic proximity that has been documented in the "home bias" literature. To measure social connectedness between firm and investor locations, they use the Social Connectedness Index (SCI), which is based on friendship links on Facebook. Below we provide a detailed description of the Social Connectedness Index data, which is publicly available to researchers interested in studying social networks. Kuchler et al. (2020a) show that social connections have the largest influence on

investments of small investors with concentrated holdings and on investments in firms with a low market capitalization and little analyst coverage. This is consistent with small investors having 
fewer resources for systematic analysis, and therefore relying more on word-of-mouth effects, in particular for investments in small stocks that might not be well known to all investors. Kuchler et al. (2020a) find no evidence that investors generate differential returns from investments in locations to which they are socially connected. Together, these findings suggest that social networks influence investment choices by improving investors' awareness of informationally-opaque firms, not by providing them with an information advantage.

Kuchler et al. (2020a) also find that the response of investment decisions to social connectedness affects equilibrium capital market outcomes: firms in locations with stronger social ties to places with substantial institutional capital have higher institutional ownership, higher valuations, and higher liquidity. These effects of "social proximity to capital" on capital market outcomes are largest for small firms with little analyst coverage. These findings provide the first evidence that social interactions in investment decisions can be important enough to affect equilibrium asset market outcomes. These results suggest that the social structure of regions affects firms' access to capital and contributes to geographic differences in economic outcomes.

One interesting contrast between the findings of Kuchler et al. (2020a) and those in Pool et al. (2015) is that, while both papers find that professional investors are affected by parts of their social networks, only Pool et al. (2015) find evidence that this behavior allows the investors to outperform. These findings are consistent with a story in which only some social connections convey useful information - in this case, the professional network measured by Pool et al. (2015), but not the friend network measured by Kuchler et al. (2020a) - even though investment behavior responds to both.

\section{Peer Effects in Household Savings and Borrowing}

In this last section, we review a number of research papers that have studied peer effects across a range of other household financial decisions, ranging from retirement savings decisions to the decision of defaulting on unsecured credit.

\subsection{Peer Effects in Retirement Savings}

A large literature explores how peer effects affect retirement savings — a decision at the intersection of households' saving decisions and their choices as individual investors in capital markets. This work has examined how peers influence coworkers' choices to participate in retirement savings plans, as well as their allocation decisions within these plans. Since these decisions usually involve choices that are common among a set of work peers, one might naturally expect those choices to be a topic of discussion at work.

In this literature, Duflo \& Saez (2002) were among the first to establish evidence of peer influence on enrollment decisions in tax-advantaged retirement savings plans among university employees. In follow-on work, the same authors conducted a randomized experiment to confirm the presence of positive social effects on enrollment choices within a large university's retirement savings plan (Duflo \& Saez, 2003).

However, the overall evidence for the magnitude and direction of peer effects in retirement 
savings decisions is somewhat mixed. For example, Beshears et al. (2015) find that individuals actually decrease their retirement plan contributions when given information about the contributions of their peers. The authors attribute this (perhaps surprising) negative effect to discouragement from upward social comparisons. In particular, the authors speculate that information about peers' savings choices discourages low-income employees by making their relative economic status more salient. In a different setting, Lieber \& Skimmyhorn (2018) do not find strong evidence of peer effects in retirement investing of soldiers. These authors exploit the randomization of individuals into different military units (and thus social settings) to provide credible identification; they conclude that the lack of noticedable peer effects may be due to the limited observability of peers' retirement decisions.

\subsection{Peer Effects in Household Borrowing and Default}

Several recent studies have also documented an important role of peer behavior in explaining household borrowing and default decisions beyond the effects on mortgage default, which we have reviewed above.

A first strand of the literature shows how a desire to "keep up with the Joneses" can induce households to take on additional consumer debt to finance consumption. For example, Georgarakos et al. (2014) use survey data to establish that individuals who perceive themselves as earning less than the average of their peers have a higher probability of borrowing. They also have larger outstanding debt amounts conditional on borrowing and a greater likelihood of running into financial distress. Similarly, Agarwal et al. (2016) explore data from Canada and find that an individual's lottery win increases subsequent borrowing and bankruptcies among the lottery winner's neighbors, with the effects increasing in the size of the lottery win. The authors also provide evidence that suggests that the increased debt is used to finance conspicuous consumption. This finding is consistent with the evidence in Bertrand \& Morse (2016), who show that poorer households consume a larger share of their current income when exposed to higher income at the top of the local income distribution. It also aligns with the findings of Kuhn et al. (2011), who explore a Dutch lottery setting to show that when a neighbor wins the lottery, this increases the car consumption of non-winning neighbors.

In addition to these papers exploring the effect of a person's positive income shock on the behavior of her peers, a related literature explores the effects of peer financial distress on individuals' own behaviors. For example, Agarwal et al. (2017) analyze data from Singapore to show that an individual's spending declines when a neighbor living in the same building experiences bankruptcy. They find that most of the reduction in spending is happening in non-conspicuous categories, suggesting that the effects are at least in part explained by the neighbor learning about the cost of default, rather than by reduced status competition with the neighbor. Similarly, Kalda (2020) shows that peer financial distress leads to a decline in individual leverage and debt on average. This decline occurs as individuals borrow less on the intensive margin, pay higher fractions of their debt, and save more while their income remains unchanged. As a result, individuals are less likely to default during the period following peer distress. The heterogeneity in responses 
suggests the role of changes in beliefs and preferences as part of the underlying mechanism. In related work using data from a Chinese online lender, Li et al. (2019) show that the default decision of a person can predict subsequent defaults of her peers.

\section{New Data: The Social Connectedness Index}

Data from online social networking services such as Facebook and LinkedIn can substantially advance our understanding of the economic and financial effects of social networks. However, working with deidentified micro data involves substantial legal and administrative constraints. To widen access to useful social network data, Bailey et al. (2018b) introduced the Social Connectedness Index, which is publicly available.

The Social Connectedness Index (SCI) measures the social connectedness across any two locations. It is based on deidentified administrative data on Facebook's social graph — which captures the network of friendship links on the platform - with users matched to their geographic locations. The SCI between regions $i$ and $j$ corresponds to the total number of connections between individuals living in region $i$ and individuals living in region $j$, given by FB_Connections $s_{i, j}$, divided by the product of the number of eligible Facebook users in those zip codes, as in equation 1. This measure captures the relative probability of a Facebook friendship link between a given user in zip code $i$ and a given user in zip code $j$ :

$$
S C I_{i, j}=\frac{F B \_ \text {Connections }_{i, j}}{\text { FB_Users } i \times F B \_U s e r s_{j}} .
$$

As an example, the heat maps in Figure 1 show the SCI of San Francisco County, CA (top panel) and Kern County, CA (bottom panel). For both San Francisco County and Kern County, a significant proportion of friendship links are to geographically close counties across the West Coast. Bailey et al. (2018b) show that this is a consistent pattern across the United States, with the median county having $63.9 \%$ of all friends living within 100 miles. However, there are also substantial differences in the social networks of the two counties. San Francisco is strongly connected to counties located in the Northeastern United States, while Kern County has fewer of these friendship links. Instead, Kern County's friendship network is concentrated in the West Coast and Mountain states, except for a pocket of strong connections to individuals living in Oklahoma and Arkansas, as well as links to North Dakota. The links to Oklahoma and Arkansas are likely related to past migration patterns, because Kern County was a major destination for migrants fleeing the Dust Bowl in the 1930s. The links to North Dakota are primarily to the Bakken oil fields, perhaps not surprising given that Kern County produces more oil than any other county in the United States.

As of September 2020, the Social Connectedness Index is available for measuring social networks between the following sets of location types:

- U.S. County to U.S. County

- U.S. County to Country 
- Country to Country

- GADM1 - GADM1 regions

- GADM1 - GADM2 regions for selected locations

The SCI data is freely and openly available to all interested researchers and policy makers at https://data.humdata.org/dataset/social-connectedness-index.

\section{Figure 1: Social connectedness to San Francisco County, CA and Kern County, CA}
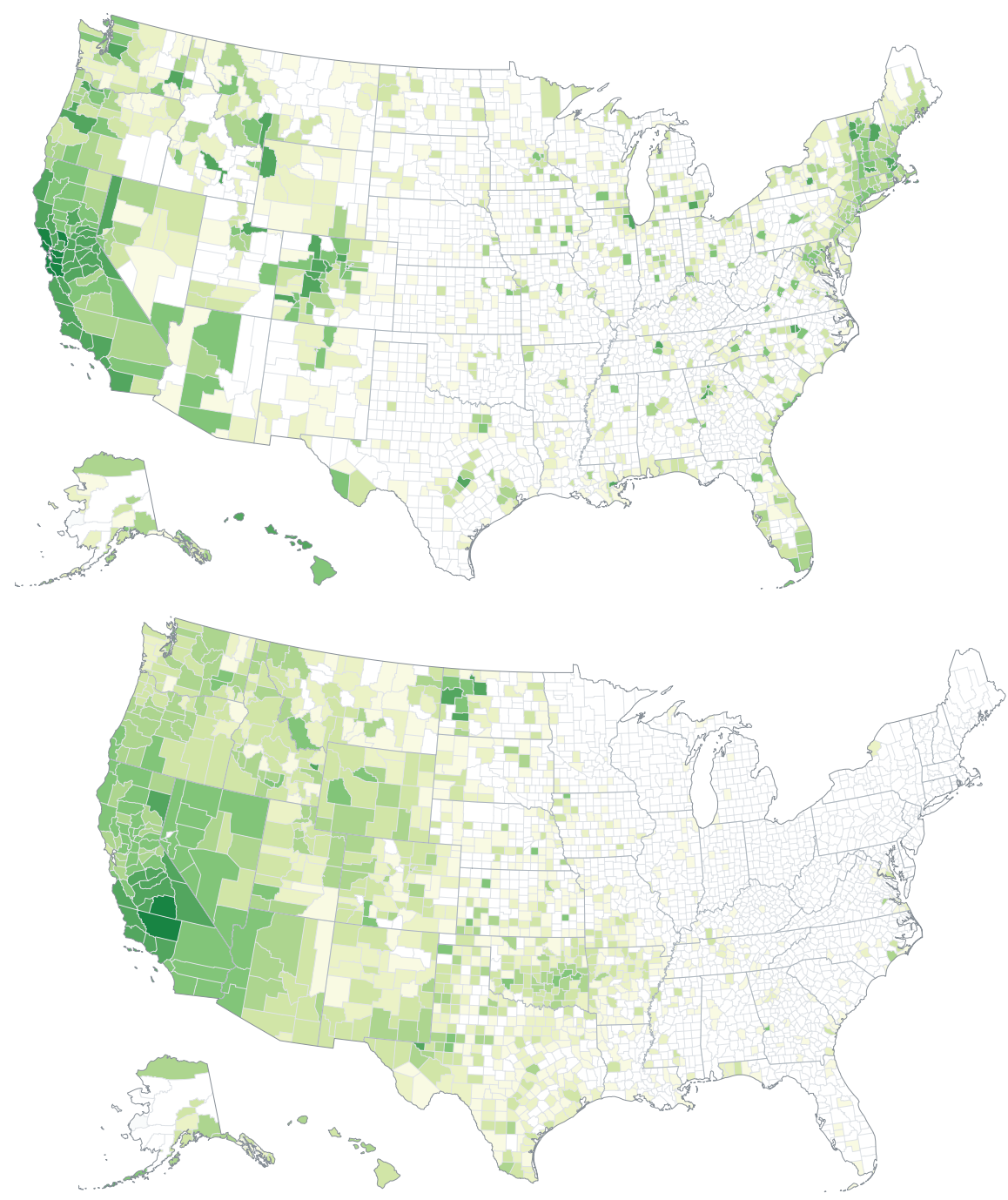

Note: Figure shows a heatmap of the social connectedness to San Francisco County, CA in the top panel, and a heatmap of the social connectedness to Kern County, CA in the bottom panel.

In addition to the papers discussed in this article, the Social Connectedness Index has been widely used by researchers across the social sciences. For example, Bailey et al. (2020b) show that social connectedness between regions and countries leads to higher trade and financial flows, Bailey 
et al. (2020a) analyze the role of transportation infrastructure in shaping urban social connectedness, Wilson (2019) studies the effects of social networks on EITC claiming behavior, Enke et al. (2019) use the SCI to study the formation of ideology, and Bailey et al. (2020c) explore how intraEuropean connectedness relates to anti-European Union sentiment. Bali et al. (2018) use the SCI data to argue that retail investors' attraction to lottery stocks is amplified by social interactions. Researchers have also used the SCI data to study the role of social interactions in credit markets: Rehbein et al. (2020) study bank lending, while Allen et al. (2020) explore credit allocation on FinTech platforms. The Social Connectedness Index has also been used to study the spread of and behavioral response to COVID-19 (e.g., Coven \& Gupta, 2020; Holtz et al., 2020; Kuchler et al., 2020b; Milani, 2020).

\section{Social Finance: A Research Agenda}

Classic models of economic behavior have not traditionally featured a role for social interactions between individuals. But, as Aristotle famously noted, humans are, by nature, social animals. As a result, interactions with other individuals are likely to influence most decisions we make through a variety of channels beyond market prices. In this paper, we have reviewed a large and growing literature that has explored the role of social interactions and peer effects in household decision making. Many of these advances have been facilitated by an increasing accessibility of novel data sets that allow researchers to overcome the measurement and identification challenges inherent in empirical work in the field of social finance. The overall conclusion from this review is that peer effects in household financial decisions are pervasive, large in magnitude, and come through several channels, including "social information" and "social utility" channels. We expect researchers to continue to add to this body of evidence over the coming years.

With a few notable exceptions, there has been less work to integrate social interactions into our theoretical modeling efforts. As social scientists, we should aim to write models that capture important features of the world, and the accumulation of evidence on the importance of social interactions suggests that an increased focus on these mechanisms might improve modeling efforts in a number of areas. While this may be challenging and will come at the cost of some tractability, recent work has shown, for example, how incorporating epidemiological models of disease spread into a general equilibrium framework can help overcome some of the associated computational challenges. We expect the inclusion of social dynamics into equilibrium models to be a promising and fruitful area of research.

We want to conclude by discussing a few themes that we expect to become more important within this research agenda.

1. We discussed that peers can both provide useful information as well as distort investment and borrowing decisions due to social comparisons, belief contagion, and investment or consumption due to a fear of missing out (FOMO). As more evidence on the distortive dimensions of peer effects accumulates, a natural question is to what extent consumer financial regulation can and should attempt to counteract those distortions (Agarwal et al., 2015). 
2. Most of the research reviewed above focuses on studying a particular peer group, such as work colleagues or geographic neighbors. An interesting next step for empirical research is to explore which types of peers are most important in which settings. Am I more likely to listen to stock market tips from my family members, my college friends, or my work colleagues? Am I more affected by individuals my age, or by older individuals? Am I more likely to trust the advice of peers who are more educated than I am?

3. While a number of studies have shown the presence of peer effects in individual behavior, most of this work has not explored the effects of this behavior on aggregate quantities and prices (see Kuchler et al., 2020a, for an exception). Do peer effects "wash out" when aggregating, or do they lead to large cyclical movements in asset prices, as suggested by Robert Shiller? Additional evidence on the aggregate implications of peer effects will help with encouraging other economists to incorporate these peer effects in their modeling efforts.

\section{References}

Abel AB. 1990. Asset prices under habit formation and catching up with the joneses. The American Economic Review 80:38-42

Agarwal S, Chomsisengphet S, Mahoney N, Stroebel J. 2015. Regulating consumer financial products: Evidence from credit cards. The Quarterly Journal of Economics 130:111-164

Agarwal S, Mikhed V, Scholnick B. 2016. Does inequality cause financial distress? evidence from lottery winners and neighboring bankruptcies

Agarwal S, Qian W, Zou X. 2017. Thy neighbor's misfortune: Peer effect on consumption. Available at SSRN 2780764

Allen L, Peng L, Shan Y. 2020. Social networks and credit allocation on fintech lending platforms. Available at SSRN

Arrondel L, Calvo Pardo HF, Giannitsarou C, Haliassos M. 2019. Informative social interactions. Available at SSRN 3171564

Bailey M, Cao R, Kuchler T, Stroebel J. 2018a. The economic effects of social networks: Evidence from the housing market. Journal of Political Economy 126:2224-2276

Bailey M, Cao R, Kuchler T, Stroebel J, Wong A. 2018b. Social connectedness: Measurement, determinants, and effects. Journal of Economic Perspectives 32:259-80

Bailey M, Dávila E, Kuchler T, Stroebel J. 2019a. House price beliefs and mortgage leverage choice. The Review of Economic Studies 86:2403-2452

Bailey M, Farrell P, Kuchler T, Stroebel J. 2020a. Social connectedness in urban areas. Journal of Urban Economics :103264 
Bailey M, Gupta A, Hillenbrand S, Kuchler T, Richmond R, Stroebel J. 2020b. International trade and social connectedness. Working Paper

Bailey M, Johnston D, Kuchler T, Stroebel J, Wong A. 2019b. Peer effects in product adoption. National Bureau of Economic Research Working Paper No. 25843

Bailey M, Kuchler T, Russel D, State B, Stroebel J. 2020c. The determinants of social connectedness in europe. Social Informatics

Bali TG, Hirshleifer DA, Peng L, Tang Y. 2018. Attention, social interaction, and investor attraction to lottery stocks, In 9th Miami Behavioral Finance Conference

Bayer P, Mangum K, Roberts JW. 2016. Speculative fever: Investor contagion in the housing bubble. Tech. rep., National Bureau of Economic Research

Bellet C. 2019. The mcmansion effect: Top size inequality, house satisfaction and home improvement in us suburbs. House Satisfaction and Home Improvement in US Suburbs (April 25, 2019)

Bertrand M, Morse A. 2016. Trickle-down consumption. Review of Economics and Statistics 98:863879

Beshears J, Choi JJ, Laibson D, Madrian BC, Milkman KL. 2015. The effect of providing peer information on retirement savings decisions. The Journal of finance 70:1161-1201

Bikhchandani S, Hirshleifer D, Welch I. 1992. A theory of fads, fashion, custom, and cultural change as informational cascades. Journal of political Economy 100:992-1026

Brown JR, Ivković Z, Smith PA, Weisbenner S. 2008. Neighbors matter: Causal community effects and stock market participation. The Journal of Finance 63:1509-1531

Burnside C, Eichenbaum M, Rebelo S. 2016. Understanding booms and busts in housing markets. Journal of Political Economy 124:1088-1147

Bursztyn L, Ederer F, Ferman B, Yuchtman N. 2014. Understanding mechanisms underlying peer effects: Evidence from a field experiment on financial decisions. Econometrica 82:1273-1301

Cohen L, Frazzini A, Malloy C. 2008. The small world of investing: Board connections and mutual fund returns. Journal of Political Economy 116:951-979

Coven J, Gupta A. 2020. Disparities in mobility responses to covid-19. Tech. rep., NYU Stern Working Paper

Duesenberry JS, et al. 1949. Income, saving, and the theory of consumer behavior

Duflo E, Saez E. 2002. Participation and investment decisions in a retirement plan: The influence of colleagues' choices. Journal of public Economics 85:121-148 
Duflo E, Saez E. 2003. The role of information and social interactions in retirement plan decisions: Evidence from a randomized experiment. The Quarterly journal of economics 118:815-842

Enke B, Rodríguez-Padilla R, Zimmermann F. 2019. Moral universalism and the structure of ideology

Feng L, Seasholes MS. 2004. Correlated trading and location. The Journal of Finance 59:2117-2144

Frydman C. 2015. Relative wealth concerns in portfolio choice: neural and behavioral evidence. Available at SSRN 2561083

Georgarakos D, Haliassos M, Pasini G. 2014. Household debt and social interactions. The Review of Financial Studies 27:1404-1433

Guiso L, Sapienza P, Zingales L. 2013. The determinants of attitudes toward strategic default on mortgages. The Journal of Finance 68:1473-1515

Gupta A. 2019. Foreclosure contagion and the neighborhood spillover effects of mortgage defaults. The Journal of Finance 74:2249-2301

Hirshleifer D. 2020. Presidential address: Social transmission bias in economics and finance. The Journal of Finance

Holtz D, Zhao M, Benzell SG, Cao CY, Rahimian MA, et al. 2020. Interdependence and the cost of uncoordinated responses to covid-19

Hong H, Kubik JD, Stein JC. 2004. Social interaction and stock-market participation. The journal of finance 59:137-163

Hong H, Kubik JD, Stein JC. 2005. Thy neighbor's portfolio: Word-of-mouth effects in the holdings and trades of money managers. The Journal of Finance 60:2801-2824

Hvide HK, Östberg P. 2015. Social interaction at work. Journal of Financial Economics 117:628-652

Ivković Z, Weisbenner S. 2007. Information diffusion effects in individual investors' common stock purchases: Covet thy neighbors' investment choices. The Review of Financial Studies 20:1327-1357

Jackson MO. 2010. Social and economic networks. Princeton university press

Kalda A. 2020. Peer financial distress and individual leverage. The Review of Financial Studies 33:3348-3390

Kaustia M, Knüpfer S. 2012. Peer performance and stock market entry. Journal of Financial Economics 104:321-338

Kuchler T, Peng L, Stroebel J, Li Y, Zhou D. 2020a. Social proximity to capital: Implications for investors and firms. Tech. rep. Working paper 
Kuchler T, Russel D, Stroebel J. 2020b. The geographic spread of covid-19 correlates with structure of social networks as measured by facebook. Tech. rep., National Bureau of Economic Research

Kuhn P, Kooreman P, Soetevent A, Kapteyn A. 2011. The effects of lottery prizes on winners and their neighbors: Evidence from the dutch postcode lottery. American Economic Review 101:222647

Kurlat P, Stroebel J. 2015. Testing for information asymmetries in real estate markets. The Review of Financial Studies 28:2429-2461

Li E, Liao L, Wang Z, Wang X. 2019. Peer effect on consumer default decision: Evidence from online lending platform. Available at SSRN 3399515

Lieber EM, Skimmyhorn W. 2018. Peer effects in financial decision-making. Journal of Public Economics 163:37-59

Manski CF. 1993. Identification of endogenous social effects: The reflection problem. The review of economic studies 60:531-542

Maturana G, Nickerson J. 2019. Teachers teaching teachers: The role of workplace peer effects in financial decisions. The Review of Financial Studies 32:3920-3957

McCartney WB, Shah A. 2019. The economic importance of neighbors: Evidence from hyperlocal social influence effects in mortgage markets. Available at SSRN 2882317

McPherson M, Smith-Lovin L, Cook JM. 2001. Birds of a feather: Homophily in social networks. Annual review of sociology 27:415-444

Milani F. 2020. Covid-19 outbreak, social response, and early economic effects: A global var analysis of cross-country interdependencies. medRxiv

Mobius MM, Niehaus P, Rosenblat TS. 2005. Social learning and consumer demand. Harvard University, mimeograph. December

Ouimet P, Tate G. 2020. Learning from coworkers: Peer effects on individual investment decisions. The Journal of Finance 75:133-172

Piazzesi M, Schneider M, Stroebel J. 2020. Segmented housing search. American Economic Review

Pool VK, Stoffman N, Yonker SE. 2015. The people in your neighborhood: Social interactions and mutual fund portfolios. The Journal of Finance 70:2679-2732

Rehbein O, Rother S, et al. 2020. Distance in bank lending: The role of social networks. Tech. rep., University of Bonn and University of Mannheim, Germany

Shiller RJ. 2000. Irrational exuberance. Princeton University Press 
Shiller RJ. 2007. Understanding recent trends in house prices and home ownership. Tech. rep., National Bureau of Economic Research

Shiller RJ, Pound J. 1989. Survey evidence on diffusion of interest and information among investors. Journal of Economic Behavior \& Organization 12:47-66

Stroebel J. 2016. Asymmetric information about collateral values. The Journal of Finance 71:10711112

Towe C, Lawley C. 2013. The contagion effect of neighboring foreclosures. American Economic Journal: Economic Policy 5:313-35

Wilson R. 2019. The impact of social networks on eitc claiming behavior 